\title{
Correction to: Effects of zinc oxide nanoparticles on arsenic stress in rice (Oryza sativa L.): germination, early growth, and arsenic uptake
}

\author{
Fan $\mathrm{Wu}^{1} \cdot$ Qing Fang ${ }^{1} \cdot$ Shiwei Yan ${ }^{1} \cdot$ Ling Pan $^{2} \cdot$ Xianjin Tang ${ }^{3} \cdot$ Wenling Ye $\mathrm{P}^{1,3}$ \\ Published online: 19 April 2021 \\ (C) Springer-Verlag GmbH Germany, part of Springer Nature 2021
}

Correction to: Environmental Science and Pollution Research (2020) 27:26974-26981 https://doi.org/10.1007/s11356-020-08965-0

While reviewing our article published online 08 May, 2020, we found that Figure S3. in the original publication was erroneously plotted due to the authors' carelessness. The authors have rechecked the raw data carefully and would like to make a correction to this figure with the updated one shown as below. This corrigendum does not affect the discussion and conclusions of the original paper. The authors would like to apologize for any inconvenience caused.

Correct Figure S3 is shown in this paper.

The online version of the original article can be found at https://doi.org/ 10.1007/s11356-020-08965-0

\footnotetext{
Xianjin Tang

xianjin@zju.edu.cn

$\triangle$ Wenling Ye

wlye@ahau.edu.cn

1 Anhui Province Key Laboratory of Farmland Ecological Conservation and Pollution Prevention, School of Resources and Environment, Anhui Agricultural University, 130 Changjiang West Road, Hefei 230036, Anhui, People's Republic of China

2 College of Marine Ecology and Environment, Shanghai Ocean University, Shanghai, People's Republic of China

3 Key Laboratory of Environment Remediation and Ecological Health, (Zhejiang University), Ministry of Education, Zhejiang, China
} 




Figure S3. The curve of the rate of As adsorption by different concentration of zinc oxide nanoparticles.

Publisher's note Springer Nature remains neutral with regard to jurisdictional claims in published maps and institutional affiliations. 